Dalen JE (1998) "Conventional" and "unconventional" medicine. Can they be integrated? Archives of Internal Medicine 158, 2179-2181.

Fontanarosa PB \& Lundberg GD (1997) Complementary, alternative, unconventional, and integrative medicine. Journal of the American Medical Association 278, 2111-2112.

Gibson GR \& Roberfroid MB (1995) Dietary modulation of the human colonic microbiota: introducing the concept of prebiotics. Journal of Nutrition 125, 1401-1412.

Hamilton-Miller JMT (1996) Probiotics - panacea or nostrum? British Nutrition Foundation Nutrition Bulletin 21, 199-208.

Hamilton-Miller JMT, Shah S \& Smith C (1996) "Probiotic" remedies are not what they seem. British Medical Journal 312, 55-56.

Hamilton-Miller JMT, Shah S \& Winkler JT (1999) Public health issues arising from microbiological and labelling quality of foods and supplements containing probiotic organisms. Public Health Nutrition (In the Press).
Hasler CM (1998) Prebiotics and probiotics, where are we today? British Journal of Nutrition 80 (Suppl. 2), S195-S233.

Hughes VL \& Hillier SL (1990) Microbiologic characteristics of Lactobacillus products used for colonization of the vagina. Obstetrics and Gynecology 75, 244-248.

Kmietowicz Z (1997) Complementary medicine should be integrated into the NHS. British Medical Journal 315, 1113.

Lee YK \& Salminen S (1995) The coming of age of probiotics. Trends in Food Science and Technology 6, 241-245.

Ramos-Remus C \& Russell AS (1997) Alternative therapies medicine, magic, or quackery. Who is winning the battle? Journal of Rheumatology 24, 2276-2278.

Salminen S, Laine M, von Wright A, Vuopio-Varkila J, Korhonen T \& Mattila-Sandholm T (1996) Development of selection criteria for probiotic strains to assess their potential in functional foods: a Nordic and European approach. Bioscience Microflora 15, 61-67.

Sanders ME, (1998) Development of consumer probiotics for the US market. British Journal of Nutrition 80 (Suppl. 2), S213-S218.

\title{
Efficacy studies of probiotics: a call for guidelines - reply by Sanders
}

Hamilton-Miller \& Gibson (1999) make some excellent points in their letter regarding the importance (and difficulty) of clinical evaluation of probiotic bacteria and of delivering suitable levels of active bacteria. I would like to clarify my perspective on delivery of probiotic bacteria in dietary supplement (pill) format to foods.

Either format can be effective in delivering therapeutic levels of viable probiotic bacteria. It is a fact, however, that current probiotic levels in some dairy products require consumption of a large volume of product to achieve therapeutic daily doses of probiotic. This is not inherent to probiotic-containing food products, per se, but only to current formulation practices, which in the USA generally target about $10^{6} / \mathrm{ml}$ or $\mathrm{g}$ at the end of shelflife. Concentration technology makes formulation of dried dietary supplements at much higher dose levels achievable, but in practice not all supplements deliver the high levels they claim, as documented by HamiltonMiller and his colleagues, among others. To add to the problem, the consumer has no resource to sort out products with high levels from those with low levels. What this suggests is that, considering current practices, there is room for improvement of probiotic delivery in both formats.

Is there an advantage to the consumer of one vehicle over the other? A case can be made that the delivery of probiotic bacteria as components of fermented dairy products (or other foods), as long as levels are sufficiently high, may be preferable. In addition to delivery of high probiotic cell numbers, fermented dairy products provide a nutrient-dense food source, including high quality protein, calcium, vitamins, and a plethora of recently identified ingredients that have been proposed to provide additional healthful attributes, such as antimicrobial fermentation endproducts, physiologically active peptides and proteins, anticarcinogenic conjugated linoleic acid and sphingolipids, and perhaps others not yet discovered. On the other hand, dietary supplement products may be more convenient at delivering biotherapeutic concentrations of probiotic bacteria to patients suffering from disease (especially in a clinical setting) and for those preferring this format. Dietary supplements may also be blended with other functional ingredients to enhance their value to the consumer.

This discussion, of course, is predicated on the assumption that viable count in the product is the relevant criterion in determining a functional dose of probiotic. In fact, this may be a gross oversimplification, as strainspecific and target-specific characteristics such as survival through the stomach and small intestine, the ability to replicate in vivo, the specific active component by which the probiotic delivers the effect on the target (viable cell, cellular enzymes, cell wall components, fermentation byproducts), all may or may not be accurately reflected by initial viable count. These facts further complicate the identification and description of an effective 'dose'.

The challenge in the probiotic-containing food market, including the USA market, is for food formulators to be convinced of the value of potent concentrations of probiotic bacteria, and develop processes and formulations which deliver high, stable concentrations of probiotic bacteria as part of healthy foods. More conclusive clinical evaluations, and understanding of mechanisms of probiotic effect and improvement of strain stability characterists will provide the evidence food manufacturers need to be persuaded. In general, meaningful measures of probiotic activity in humans (reduction of incidence, duration or severity of diarrhoea, improved digestion of lactose in intolerant populations, reduction in mutagenic/carcinogenic activities) have required high daily consumption $\left(10^{9}-10^{11}\right.$ probiotic bacteria). Changes in other bio-indicators (e.g. faecal flora populations) may occur at lower levels of feeding $\left(10^{8} / \mathrm{d}\right)$, but these changes have not been clearly correlated with a physiological effect. Until the dose studies have been conducted and the active component better defined, I believe it is prudent to assume that the higher levels are generally necessary for a meaningful, physiological effect. 
M. E. Sanders

Dairy and Food Culture Technologies

Littleton

Colorado

USA

and

Dairy Products Technology Center

California Polytechnic State University
San Luis Obispo

California

USA

\section{Reference}

Hamilton-Miller JMT \& Gibson GR (1999) Efficacy studies of probiotics: a call for guidelines (letter). British Journal of Nutrition 82, 73-74.

\section{Functional food properties of non-digestable oligosaccharides}

We were very interested to read the papers by Gibson et al. (1999) and the ENDO project group (Van Loo et al. 1999) in the February issue of the British Journal of Nutrition. They give a useful introduction to the field and list over a dozen different potential health advantages of altered gut bacteriology. When we last attempted to prepare a list of physiological actions of fermentable substrates on the hindgut we gave up after thirty. One of these actions, which was not mentioned in the two papers, was the stimulation of cell proliferation in the intestinal mucosa by the production of short-chain fatty acids (SCFA). There is substantial confusion on the actions of the SCFA, as in vitro studies have shown them to be powerful stimulators of differentiation and apoptosis; however, in vivo they are clearly powerful mitogens (Goodlad et al. 1989), moreover there is poor evidence for pro-apoptotic effects in vivo. The implications of this significant proliferative effect are as yet still unclear, but increased proliferation is traditionally regarded as a potential risk factor in the development of carcinogenesis (Wasan et al. 1996). Fermentation in the colon also has other biological-cellular actions on the process of crypt fission (McCullough et al. 1998), which we have implicated as a critical event in the initiation-development of colorectal carcinogenesis (Wasan et al. 1997).

It would appear that this consensus paper is somewhat biased towards the positive evidence, and one must be clearly aware that most clinical dietary interventions have not had the intended beneficial outcomes. This is especially worth stressing in light of the unanticipated results of most of the randomized human $\beta$-carotene studies, vitamins $C$ and $\mathrm{E}$ and fibre-polyp prevention studies. In these human clinical trials, either no benefits were seen or, more worryingly, detrimental, (i.e. pro-carcinogenic) effects were observed, which led to the early closure of some of the studies (ATBC, 1994). Thus no prospective human clinical study has ever confirmed the purported theoretical benefits. Indeed, worryingly, a fair proportion of dietary fibre studies in animals have also shown pro-carcinogenic effects (Hill et al. 1996).

A further complication may be that the addition of fermentable substrate supplements to a 'Western' diet may result in a feast or famine pattern of fermentation (McBurney et al. 1987) in which there are sudden surges in bacteriological activity followed by a lack of substrate, in which case the colonic flora must either ferment each other (cannibalism) or the colonic epithelial mucosa and mucins.

We therefore agree with the ENDO group that there is a great need for more in-depth research, but would caution against over enthusiasm in instigating human trials based on the currently available scientific data.

Robert A. Goodlad

Principal Scientific Officer Imperial Cancer Research Fund and Senior Lecturer

Imperial College of Science, Technology and Medicine

DuCane Road

London W12 ONN

United Kingdom

Harpreet Wasan

Senior Lecturer and Honorary Consultant in Medical Oncology Imperial College of Science, Technology and Medicine DuCane Road, London W12 ONN United Kingdom

\section{References}

ATBC (1994) The effect of Vitamin E and beta carotene on the incidence of lung cancer and other cancers in male smokers. The Alpha-Tocopherol, Beta Carotene Cancer Prevention Study Group. New England Journal of Medicine 330, 1029-1035.

Gibson GR \& Williams CM (1999) Gut fermentation and health advantages: myth or reality? (Invited commentary). British Journal of Nutrition 81, 83-84.

Goodlad RA, Ratcliffe B, Fordham JP \& Wright NA (1989) Does dietary fibre stimulate intestinal epithelial cell proliferation in germ-free rats? Gut 30, 820-825.

Hill MJ \& Leeds AR (1996) Reply to Wasan \& Goodlad. Lancet 348, 957.

McBurney MI, Van Soest PJ \& Jeraci JL (1987) Colonic carcinogenesis: the microbial feast or famine mechanism. Nutrition and Cancer 10, 23-28.

McCullough JS, Ratcliffe B, Mandir N, Carr KE \& Goodlad RA (1998) Dietary fibre and the intestinal microflora, effects on intestinal morphometry and crypt branching. Gut 42, 799-806.

Van Loo J, Cummings J, Delzenne N, Englyst H, Franck A, Hopkins M, Kok N, Macfarlane G, Newton D, Quigley M, Roberfroid M, van Vliet T \& van den Heuvel E (1999) Functional food properties of non-digestible oligosaccharides: a concensus report from the ENDO project (DGXII AIRII-CT 94-1095). British Journal of Nutrition 81, 121-132.

Wasan H \& Goodlad RA (1996) 'Fibre' supplemented foods may damage your health. Lancet 348, 319-320.

Wasan H, Park HS, Liu KC, Mandir N, Winnett A, Sasieni P, Bodmer W, Goodlad RA \& Wright N 91997) APC in the regulation of intestinal crypt fission. Gut 40, A45. 